\title{
In vivo insulin resistance in streptozotocin-diabetic rats - evidence for reversal following oral vanadate treatment
}

\author{
O. Blondel, D. Bailbe and B. Portha \\ Laboratoire de Physiologie du Développement, CNRS UA 307, Université Paris 7, Paris, France
}

\begin{abstract}
Summary. Hepatic glucose production and peripheral glucose utilisation were measured in vivo with the euglycaemic-hyperinsulinaemic clamp technique in rats rendered severely diabetic with streptozotocin $(45 \mathrm{mg} / \mathrm{kg})$ and in control rats. The rats were studied in the post-absorptive state while anaesthetised. The basal glucose production and glucose utilisation were significantly higher $(p<0.001)$ in diabetic rats 9 days after streptozotocin administration. During the clamp studies, suppression of glucose production by the liver induced by submaximal or maximal insulin levels was significantly less ( $p<0.01$ and $p<0.001$ respectively) effective in diabetic rats as compared to control rats. Glucose utilisation was significantly lower following both submaximal $(p<0.01)$ or maximal $(p<0.001)$ hyperinsulinaemia as compared to control rats. Oral administration of vanadate $(0.2 \mathrm{mg} / \mathrm{ml}$ in drinking water) for a 20 -day period in diabetic rats lowered their plasma glucose levels to normal near values within 4 days, normalised plasma insulin levels, and increased pancreatic insulin stores. The rate of glucose disappearance ( $K$ value) and in vivo glucose-induced insulin secretion as estimated during
\end{abstract}

an i.v. glucose tolerance test were not significantly improved. In control rats, vanadate treatment did not significantly affect any of the above parameters. In vanadate treated diabetic rats, basal glucose production was normalised. Following submaximal or maximal hyperinsulinaemia, glucose production was suppressed normaly. Basal glucose utilisation was restored and returned to normal values during submaximal hyperinsulinaemia. However, during maximal hyperinsulinaemia, glucose utilisation still remained significantly lower $(p<0.05)$ as compared to vanadate-treated control rats. Vanadate treatment in control rats did not affect significantly any of the above parameters. These results show an insulin-like effect of vanadate upon glucose metabolism in vivo in the liver and peripheral tissues of diabetic rats, leading to normalisation of glycaemia in the absence of any significant improvement of insulin secretion.

Key words: Streptozotocin-diabetic rats, glucose production, glucose utilisation, insulin resistance, vanadate.
Heyliger et al. [1] reported that the inclusion of sodium vanadate in the drinking water of streptozotocin (STZ) diabetic rats alleviated some symptoms of diabetes, resulting in the normalisation of blood glucose levels and the diminution of depressed cardiac performance. Sodium vanadate did not increase serum insulin levels [1] suggesting that insulin target tissues themselves are the site of vanadate action. This observation has been recently confirmed and further characterised by Meyerovitch et al. [2]. They concluded that the adipocytes of STZ diabetic rats responded in vitro to lower insulin concentrations, and that the basal rate of hexose uptake in the liver and muscles was doubled after administration of vanadate. This would suggest that vana- date treatment improves insulin action at least in the adipose tissue of the STZ-diabetic rats.

In fact, as there is presently no direct demonstration of change of in vivo insulin action in target tissues of vanadate treated STZ-diabetic rats, and in view of the heterogeneity of insulin sensitivity among target tissues, it is clearly desirable to examine in vivo the insulin effect on the glucose disposal by the liver and the peripheral tissues in order to properly characterise the impact of vanadate.

The present study was therefore undertaken to determine the effect of oral administration of vanadate in severely STZ-diabetic rats: (1) on basal blood glucose and insulin levels, (2) on glucose tolerance and glucose-in- 
duced insulin release, and (3) on basal and insulin-stimulated in vivo glucose production and glucose utilisation, using the insulin-clamp technique in conjunction with isotopic measurement of glucose turnover.

\section{Materials and methods}

\section{Animals and treatments}

Female Wistar rats used in the study were taken from our own colony. They were weaned 28 days after birth with free access to a commercial pelleted chow (ref. 113, UAR, Villemoisson-sur-Orge, France). Insulin deficiency was induced at 2.5 months by administering streptozotocin (STZ, $45 \mathrm{mg} / \mathrm{kg}$ body weight), diluted in citrate buffer ( $\mathrm{Ph} 4.5$ ), as a single intravenous injection through the saphenous vein, under light anaesthesia (pentobarbital) and while the rats were in a non-fasted state. Nine days after the STZ administration, STZdiabetic rats and non-diabetic rats raised in parallel were given an aqueous solution of sodium metavanadate (Merck, Darmstadt, FRG, $0.2 \mathrm{mg} / \mathrm{ml}$ and $80 \mathrm{mmol} / 1 \mathrm{NaCl}$ ) for 20 days. Sodium chloride was included as it is known to reduce vanadium toxicity [1]. Vanadate solutions were replaced by freshly prepared solution every two days. The vanadate treated rats were compared to control rats, either diabetic or non-diabetic, receiving normal drinking water. We found in pilot experiments with diabetic and non-diabetic rats that drinking water containing $80 \mathrm{mmol} / 1 \mathrm{NaCl}$ for 20 days did not modify their respective basal plasma glucose levels, their basal plasma insulin levels, their pancreatic insulin content and their daily food intake (results not shown). Thus, we decided to compare the vanadate-treated groups to the respective groups receiving normal drinking water in the experiments related to in vivo glucose metabolism and insulin secretion. A glucose tolerance test (i.v. glucose $0.5 \mathrm{~g} / \mathrm{kg}$ body weight) was performed in the untreated STZ and control rats and in the vanadatetreated STZ and control rats 14 days after starting the treatment. Insulin glucose clamp studies and quantification of pancreatic insulin stores were performed in untreated STZ and control rats and in STZ and control rats at the end of the vanadate treatment (after 20 days).

\section{Glucose tolerance tests}

Intravenous glucose tolerance tests $(0.5 \mathrm{~g}$ glucose $/ \mathrm{kg}$ body weight) were performed at 14.00 hours in rats fasted from 09.00 hours under pentobarbital anaesthesia $(4 \mathrm{mg} / 100 \mathrm{~g}$ body weight intraperitoneally). Blood was withdrawn from the tail vein. Blood samples (300 $\mu 1)$ were immediately centrifuged at $4^{\circ} \mathrm{C}$ and plasma was stored at $-20^{\circ} \mathrm{C}$ until assayed.

\section{Euglycaemic insulin clamp studies}

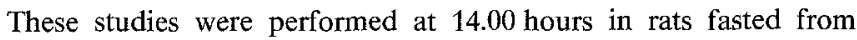
09.00 hours according to a previously detailed procedure [3]. Under these conditions, it had been shown that there was a difference in blood glucose concentration between the aorta and the portal vein in the adult rat, indicating that the gut was not adding glucose into the portal circulation from previously ingested food [4]. Therefore, the rats were considered to be in the post-absorptive period and the rate of glucose production was a measure of endogenous glucose production. Rats were anaesthetised with pentobarbital $(4 \mathrm{mg} / 100 \mathrm{~g}$ body weight i.p.). Body temperature was maintained at $37-38^{\circ} \mathrm{C}$ with heating lamps. One carotid artery was catheterised for blood sampling and a tracheotomy was performed to avoid respiratory problems during anaesthesia. A $150 \mu \mathrm{l}$ blood sample was collected 20 min after the end of surgery for the determination of the basal blood glucose. The insulin dose-response values were obtained by infusing two amounts of insulin (4.3 and $\left.23.0 \mathrm{mmol} \cdot \mathrm{h}^{-1} \cdot \mathrm{kg}^{-1}\right)$ to raise the plasma insulin levels to 3.5 and $45.0 \mathrm{nmol} / 1$ values. Insulin (porcine monocomponent insulin Actrapid, Novo, Copenhagen, Denmark) was dissolved in $0.9 \% \mathrm{NaCl}$ containing $0.2 \%$ bovine serumalbumin (Sigma, St. Louis, Mo, USA).

In experiments on rats with normal basal plasma glucose levels (control rats and vanadate-treated STZ rats), the variable glucose infusion was begun $5 \mathrm{~min}$ after starting the insulin infusion. The steadystate plasma insulin level and the steady-state blood glucose level were reached, respectively, $30 \mathrm{~min}$ and $45-50 \mathrm{~min}$ after the beginning of the insulin infusion. Blood samples of $200 \mu \mathrm{l}$ were collected at 55 , 60 and $65 \mathrm{~min}$ after commencement of the insulin infusion to determine blood glucose specific activity and plasma insulin concentrations.

In experiments on hyperglycaemic rats (untreated STZ-rats) plasma glucose was normalised before the commencement of each clamp study by a priming injection of insulin, followed by the insulin infusion $(4.3$ or $23.0 \mathrm{mmol} / \mathrm{h} / \mathrm{Kg}) 20 \mathrm{~min}$ later. This required 45-55 min.

The variable glucose infusion was started $5 \mathrm{~min}$ after the beginning of the insulin infusion. The steady-state plasma insulin level and the steady-state blood glucose level were reached 45-50 min after the beginning of insulin infusion. Blood samples of $200 \mu \mathrm{l}$ were collected at 55,60 and $65 \mathrm{~min}$ after commencement of insulin infusion to determine blood glucose specific activity and plasma insulin concentrations.

\section{Glucose utilisation and endogenous glucose production}

Glucose utilisation and endogenous glucose production in the basal state as well as during each of the glucose clamp studies were assessed by a primed continuous infusion of $\left[3-{ }^{3} \mathrm{H}\right]$ glucose (New England Nuclear, Dreieich, FRG). The labelled glucose was administered as an initial intravenous priming dose $(4 \mu \mathrm{Ci})$ followed immediately by a continuous intravenous infusion at a rate of $0.2 \mu \mathrm{Ci} / \mathrm{min}$. A steadystate of glucose specific activity was established by $40 \mathrm{~min}$ both in the basal state studies and in the clamp studies. The rate of glucose appearance $(\mathrm{Ra})$ was then equal to the rate of glucose disappearance (Rd) and these two parameters were calculated by dividing the $\left[3-{ }^{3} \mathrm{H}\right]$ glucose infusion rate $(\mathrm{dpm} / \mathrm{min})$ by the steady-state value of glucose specific activity $(\mathrm{dpm} / \mathrm{g})$. Glucose utilisation rate (GUR) by the whole body mass in the basal state, as well as during the clamp studies, is equal to the rate of glucose disappearance. In the basal state, the rate of endogenous glucose production (GPR) is equal to the rate of glucose appearance (Ra). In the clamp studies, GPR was calculated by subtracting the exogenous glucose infusion rate (GIR) from the rate of glucose appearance $(\mathrm{Ra})$.

\section{Analytical techniques and calculations}

Plasma glucose was determined using a glucose analyzer (Beckman Inc., Palo Alto, Calif., USA). Blood samples for determination of glucose specific activity were deproteinised with $\mathrm{Ba}(\mathrm{OH})_{2}-\mathrm{ZnSO}_{4}$ and immediately centrifuged. An aliquot of the supernatant was used for the determination of glucose concentration using a glucose oxidase method.

Another aliquot of the supernatant was evaporated at dryness at $60^{\circ} \mathrm{C}$ to remove tritiated water. The dry residue was dissolved in $0.2 \mathrm{ml}$ distilled water and counted with $10 \mathrm{ml}$ of Ready Solv-MP scintillation solution (Beckman). Plasma immunoreactive insulin was estimated using purified rat (studies in the basal state) or porcine (clamp studies) insulin as standards (Novo), antibody to mixed (porcine + bovine) insulin cross-reacting similarly with pork and rat insulin standards and porcine monoiodinated ${ }^{125}$ I-insulin [3]. Charcoal was used to separate free from bound hormone. The method allows the determination of 40 pmol with a coefficient of variation within and between assays of $10 \%$. 
Table 1. Weight changes, fluid and food intake, basal plasma insulin and glucose levels in vanadate treated or untreated diabetic and control rats. These parameters were determined at the end of vanadate treatment

\begin{tabular}{|c|c|c|c|c|c|c|}
\hline & $\begin{array}{l}\text { Average } \\
\text { weight gain } \\
\text { (g/day) }\end{array}$ & $\begin{array}{l}\text { Fluid } \\
\text { intake } \\
\text { (ml/day) }\end{array}$ & $\begin{array}{l}\text { Food } \\
\text { intake } \\
\text { (g/day) }\end{array}$ & $\begin{array}{l}\text { Plasma } \\
\text { glucose } \\
(\mathrm{mmol} / 1)\end{array}$ & $\begin{array}{l}\text { Plasma } \\
\text { insulin } \\
(\mathrm{nmol} / \mathrm{l})\end{array}$ & $\begin{array}{l}\text { Pancreatic } \\
\text { insulin content } \\
\text { (nmol/pancreas) }\end{array}$ \\
\hline \multicolumn{7}{|l|}{ Control rats } \\
\hline Untreated & $2.6 \pm 0.4$ & $36 \pm 3$ & $19 \pm 1$ & $6.8 \pm 0.1$ & $0.71 \pm 0.04$ & $33.8 \pm 2.0$ \\
\hline Vanadate treated & $0.7 \pm 0.5^{\mathrm{a}}$ & $21 \pm 2^{b}$ & $15 \pm 1^{\mathrm{c}}$ & $6.6 \pm 0.1$ & $0.69 \pm 0.02$ & $35.1 \pm 1.4$ \\
\hline \multicolumn{7}{|l|}{ Diabetic rats } \\
\hline
\end{tabular}

Values are mean \pm SEM of 8-17 observations in each group. General features of the experiments are described under "Materials and methods". ${ }^{\mathrm{a}} p<0.05 ;{ }^{\mathrm{b}} p<0.01 ;{ }^{\mathrm{c}} p<0.001$. Comparisons were made with values in the untreated control rats

Insulin response during the glucose tolerance test was calculated as the incremental plasma insulin values integrated over the period $(30 \mathrm{~min})$ following the injection of glucose $\left(\Delta \mathrm{I}, \mathrm{pmol} \cdot \mathrm{1}^{-1} \cdot \mathrm{min}^{-1}\right)$. The rate of glucose disappearance $(\mathrm{K})$ was calculated from the slope of the regression line obtained with the log-transformed plasma glucose values between 5 and 30 min after glucose administration; it was expressed as $\% \cdot \min ^{-1}$.

Statistical analysis. Results are given as mean \pm SEM. Statistical analysis was performed using variance analysis (ANOVA).

\section{Results}

Characteristics of animals used in the study are shown in Table 1. The fluid and food intake of the diabetic untreated rats were greater than those of the control untreated rats. Vanadate-treated rats, whether diabetic or non-diabetic, consumed significantly less $(p<0.001)$ fluid and food than untreated rats. Similar results were reported by Heyliger et al. [1] and Meyerovitch et al. [2]. But as the inclusion of vanadate in the drinking water of diabetic rats alleviated chronic glucosuria and symptoms of diabetes, a reduction of the daily fluid intake by these rats was not unexpected. Additionally, it is remarkable that average weight gain, fluid intake and food intake were not significantly different in control rats as compared to diabetic rats after 20 days of vanadate treatment (Table 1). To test the hypothesis that a reduction of daily food intake per se may affect insulin action in STZ-diabetic rats, a pilot experiment was performed using untreated STZ-diabetic rats receiving the same daily food intake as the vanadatetreated STZ-rats. In that pair-fed group, despite a slight reduction of basal plasma glucose as compared to untreated STZ rats, glucose production and glucose utilisation following submaximal hyperinsulinaemia (clamp experiments) were not significantly different from the corresponding values in the untreated STZ rats (results not shown).

As shown in Figure 1, basal plasma glucose levels of STZ-diabetic rats dropped from hyperglycaemic to near normoglycaemic levels within 4 days after vanadate treatment and, thereafter, remained stable as long as the treatment was maintained. This effect of vanadate

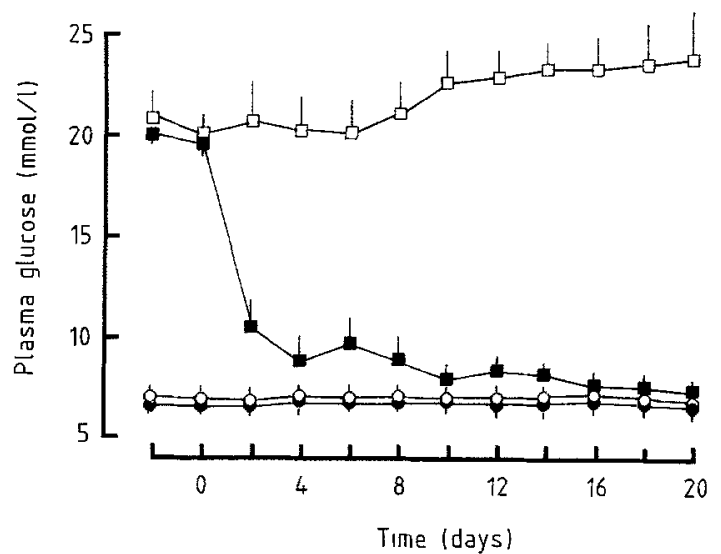

Fig. 1. Basal plasma glucose changes in STZ-diabetic rats $(\square, \boldsymbol{\square})$ and non-diabetic rats $(\mathrm{O}, \boldsymbol{\bullet})$ receiving $(\boldsymbol{\square}, \boldsymbol{\bullet})$ vanadate treatment (NaVO3 $0.2 \mathrm{mg} / \mathrm{ml}$ and $80 \mathrm{mmol} / \mathrm{l} \mathrm{NaCl}$ in drinking water) for 20 days. Comparisons were made with groups supplied with drinking water $(\square, O)$. Diabetic rats were given $\mathrm{NaVO}_{3} 9$ days after the induction of diabetes by STZ $(45 \mathrm{mg} / \mathrm{kg})$. Each point is the mean \pm SEM of $8-17$ observations in each group

administration was reversible since hyperglycaemia recurred within $24 \mathrm{~h}$ following removal of vanadate from drinking water $(12.8 \pm 0.8 \mathrm{mmol} / 1$ and $16.4 \pm 1.0 \mathrm{mmol} / 1, n=3$, in diabetic rats, respectively, 1 day and 2 days after stopping vanadate, as compared to $7.9 \pm 0.4 \mathrm{mmol} / 1$ in the same diabetic rats after a 20 day vanadate supply). Administration of vanadate to control rats did not modify significantly their basal plasma glucose and insulin levels nor their pancreatic insulin stores (Table 1). In diabetic rats, in addition to its normalising effect upon basal plasma glucose level, vanadate treatment restored basal plasma insulin levels and induced an 8 -fold increase $(p<0.001)$ in pancreatic insulin stores (Table 1).

Values of the mean incremental insulin areas during a glucose tolerance test were multiplied by 10 in the vanadate treated diabetic rats but compared to values in the untreated diabetic rats remained non-significantly different.

This parameter remained unchanged in the control groups (Fig. 2). In response to an intravenous glucose load, the $\mathrm{K}$ values remained unchanged in the diabetic and control groups (Fig. 2). 
Table 2. Blood glucose, plasma insulin, glucose and insulin infusion rates and glucose kinetics during hyperinsulinaemic euglycaemic clamp in control and STZ-diabetic rats, treated with and without vanadate

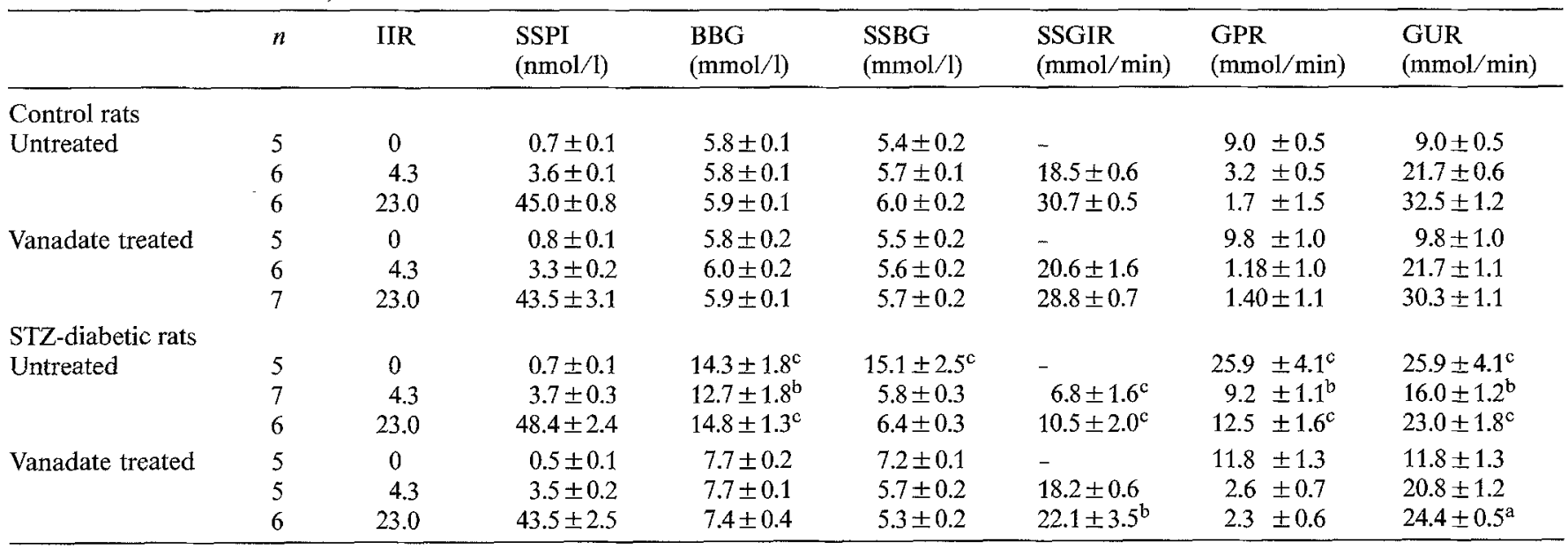

Values are mean \pm SEM. $n=$ number of rats. IIR: insulin infusion rate. SSPI: steady-stae plasma insulin. BBG: basal blood glucose. SSBG: steady-state blood glucose. SSGIR: steady-state glucose infusion rate. GPR: glucose production rate. GUR: glucose utilisation rate. ${ }^{a} p<0.05$; ${ }^{b} p<0.01 ;{ }^{c} p<0.001$ as compared to the related control rats
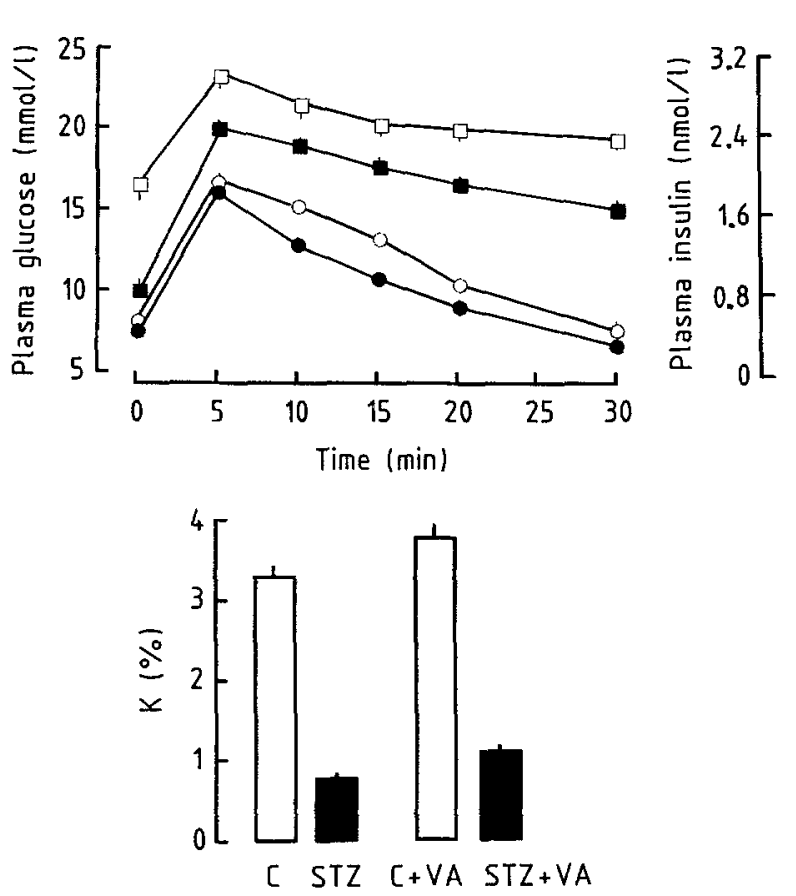
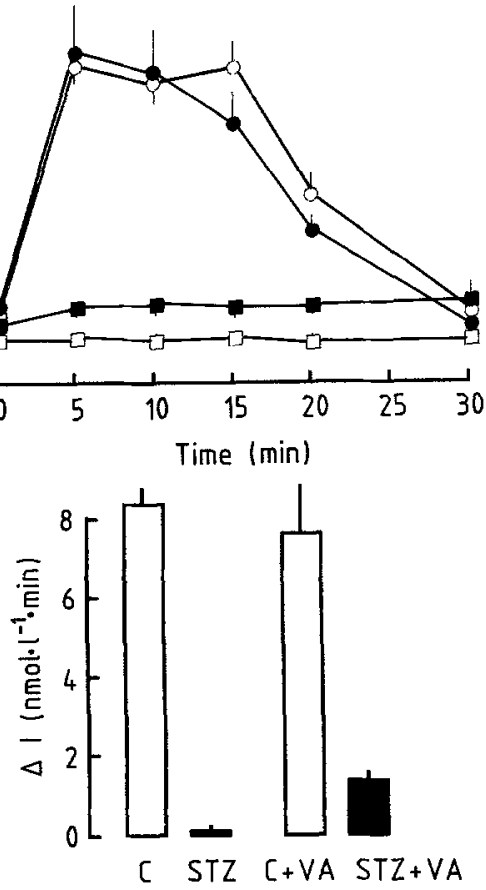

Fig. 2. Glucose tolerance and plasma insulin response to glucose $(0.5 \mathrm{~g} / \mathrm{kg}$ i.v. $)$ in STZ-diabetic rats $(\square, \square)$ or non-diabetic rats $(\mathrm{O}, \bullet)$ receiving $(\mathbf{\square}, \mathbf{0})$ or not receiving $(\square, \bigcirc)$ vanadate treatment. Rats were tested after 2 weeks of vanadate treatment. Mean incremental insulin areas $(\Delta \mathrm{I})$ and glucose disappearance rates ( $\mathrm{K}$ values) were calculated from values obtained during a $30 \mathrm{~min}$ glucose tolerance test. Each point is the mean \pm SEM of 7-11 observations in each groups
In vivo insulin action was quantified in diabetic and control rats including those treated with and without vanadate (Table 2). In the diabetic rats 9 days after STZ injection, the basal glucose production and glucose utilisation were significantly higher $(p<0.001)$ as compared to control rats. During the clamp studies, suppression of glucose production by the liver induced by submaximal or maximal insulin levels was significantly less ( $p<0.01$ and $p<0.001$ respectively) effective in the untreated diabetic rats as compared to untreated control rats. Glucose utilisation was significantly lower following both submaximal $(p<0.01)$ or maximal $(p<0.001)$ hyperinsulinaemia as compared to control rats. Following a 20-day vanadate treatment, basal rate of glucose production was significantly lower $(p<0.01)$ in vanadate-treated diabetic rats than in untreated diabetic rats. Vanadate treatment did not affect basal glucose production in the control rats. During the euglycaemic clamp experiments, following submaximal hyperinsulinaemia ( $3.5 \mathrm{mmol} / 1$ as a mean) or maximal hyperinsulinaemia $(45.0 \mathrm{mmol} / 1$ as a mean) endogenous glucose production in the vanadatetreated diabetic rats was suppressed to normal (Table 2). Vanadate treatment did not significantly modify the insulin inhibitory effect upon endogenous glucose production in the control rats (Table 2). Basal 
rate of glucose utilisation was restored in the vanadatetreated diabetic rats. Vanadate treatment did not affect the basal glucose utilisation rate in the control rats (Table 2). Following submaximal hyperinsulinaemia, the glucose utilisation by the whole body mass in the vanadate-treated diabetic rats was restored as compared to control rats (Table 2). Following maximal hyperinsulinaemia, the glucose utilisation in the vanadate-treated diabetic rats remained significantly lower $(p<0.05)$ than the corresponding utilisation in the vanadate-treated control rats (Table 2). Vanadate treatment did not significantly modify the insulin stimulatory effect upon glucose utilisation in the control rats (Table 2).

\section{Discussion}

The results clearly show that oral administration of vanadate largely normalised basal plasma glucose levels in adult rats with severe STZ-induced diabetes in accordance with recent studies [1, 2]. The basal plasma insulin levels returned to normal values, but glucose-induced insulin secretion during the glucose tolerance test, while increased, still remained not significantly different from that in untreated diabetic rats. Vanadate treated diabetic rats remained largely intolerant to glucose. The normalisation of plasma insulin levels and the very weak improvement of insulin secretion in the diabetic rats is probably related to the significant increase of the pancreatic insulin stores after vanadate treatment. Our observation that a return to clear-cut glucose-induced insulin secretion in diabetic rats after chronic vanadate treatment is in accordance with the previous report by Heyliger et al. [1]. The slight improvement of B-cell function in our protocol could be related to the normalisation of blood glucose levels, and not to a direct effect of the vanadate on the B cells. Indeed, some studies have provided evidence that hyperglycaemia per se may contribute to the defect in insulin secretion by the B cells in some animal models of diabetes [5-8]. Alternatively, it has been recently reported that vanadium acutely stimulates in vitro insulin release from normal rat islets in a concentration-dependent manner [9]. In any cases, it would be erroneous to suggest that the slight improvement in insulin secretion in diabetic rats treated with vanadate is the main mechanism contributing to normalisation of the plasma glucose level.

Another point of interest which emerges from our data is that vanadate treatment had clear-cut effects upon glucose metabolism in vivo by the liver and peripheral tissues. After 20 days of vanadate treatment, hepatic glucose production returned to normal values in diabetic rats. During the clamp studies, suppression of glucose production induced by submaximal or maximal insulin levels was restored, as compared to vanadate-treated control rats. Vanadate treatment did not af- fect significantly the above parameters in the control rats. These observations are in line with the report that vanadate treatment stimulated basal glucose uptake [2] and restored glycogen content, fructose 2,6-biphosphate concentration and glucokinase activity [10] in the liver of diabetic rats, while it was without significant effect in the liver of control rats. Concurrent with the restoration of hepatic glucose production, a clear improvement of glucose disposal had occurred in the vanadate-treated diabetic rats. Basal glucose utilisation returned to normal values. During the clamp studies, glucose utilisation induced by submaximal insulin level was again restored. Nevertheless, at maximal insulin levels, it remained significantly decreased as compared to that in control rats. Vanadate treatment did not affect significantly the above parameters in the control rats. Our observation that vanadate treatment normalises, to a large extent, in vivo glucose disposal and the tissue insulin insensitivity in severely diabetic rats agrees with a recent observation: under experimental conditions very similar to ours, Meyerovitch et al. [2] found that, subsequent to vanadate treatment, insulin binding and in vitro insulin-stimulated lipogenesis by the adipocytes isolated from diabetic rats were normalised. At the moment, the cellular mechanisms of vanadate are poorly understood, although several potential biochemical actions might explain its insulin-like effects in acute experiments. Enhanced hydrogen peroxide generation [11] or inhibition of phosphotyrosine phosphatase [12] have been proposed. Inhibition of $\mathrm{Na}^{+} / \mathrm{K}^{+}$ATPase (a widely recognised effect of vanadium [13]) in adipocytes was eliminated as the mechanism of the insulinlike effects of vanadate in these cells [14]. It was then demonstrated that vanadate as well as insulin increases the autophosphorylation and the tyrosine kinase activity of the insulin receptor in adipocytes [15]. Finally, a recent report proposed that vanadate stimulates glucose transport in adipocytes acting at a level distal to the insulin receptor [16]. In addition, vanadate could act by mediating changes in the intracellular concentration of cyclic AMP [17] and $\mathrm{Ca}^{2+}$ handling [18].

In summary, the present results confirm that severe insulin deficiency and concomitant hyperglycaemia, as the consequences of STZ administration in the adult rat, lead to the development of in vivo insulin resistance. Oral vanadate treatment normalises plasma glucose levels and improves to a large extent the insulinmediated glucose disposal and the ability of insulin to inhibit glucose output. It also normalises basal plasma insulin level while glucose induced insulin secretion is only marginally improved. Discontinuation of vanadate treatment leads to a rapid re-emergence of hyperglycaemia. The process leading to the normalisation of tissue responsiveness to insulin in vivo by vanadate is not understood. One possibility is that vanadate may interfere with the intracellular biochemical events which lead to insulin receptor upregulation and desensitisation. An alternative possibility is that the correction of 
the hyperglycaemic state per se is responsible for the observed changes, since in a recent study [19] we provided evidence that the sole restoration of normoglycaemia (in the absence of any improvement of endogenous insulin secretion) can completely correct insulin resistance involving both hepatic and peripheral tissues of diabetic rats.

Acknowledgments. We are grateful to Prof. L. Picon for helpful discussions and to Drs. E. Forgue-Lafitte and G. Rosselin (INSERM-Unité 55-Paris) for the supply of iodinated insulin. This work was partly supported by the Institut National de la Santé et de la Recherche Médicale (INSERM) (CRE n 874013).

\section{References}

1. Heyliger CE, Tahiliani AG, McNeill JH (1985) Effect of vanadate on elevated blood glucose and depressed cardiac performance of diabetic rats. Sciences $227: 1474-1477$

2. Meyerovitch J, Farvel Z, Sack J, Shechter Y (1987) Oral administration of vanadate normalizes blood glucose levels in streptozotocin-treated rats. J Biol Chem 262: 6658-6662

3. Kergoat M, Portha B (1985) In vivo hepatic and peripheral insulin sensitivity in rats with non-insulin-dependent diabetes induced with streptozotocin. Assessment with the insulin-glucose clamp technique. Diabetes 34: 1120-1126

4. Leturque A, Burnol AF, Ferre P, Girard J (1984) Pregnancy induced insulin resistance in the rat. Assessment by glucose clamp technique. Am J Physiol 245: E1-7

5. Portha B (1985) Decreased glucose-induced insulin release and biosynthesis by islets of rats with non-insulin-dependent diabetes: Effect of tissue culture. Endocrinology 117: 1735-1741

6. Leahy JL, Cooper HE, Deal DA, Weir GC (1986) Chronic hyperglycemia is associated with impaired glucose influence on insulin secretion. J Clin Invest 77: 908-915

7. Kergoat M, Bailbe D, Portha B (1987) Insulin treatment improves glucose-induced insulin release in rats with NIDDM induced by streptozotocin. Diabetes 36: 971-977

8. Rossetti L, Shulman GI, Zawalich W, De Fronzo RA (1987) Effect of chronic hyperglycemia on in vivo insulin secretion in partially pancreatectomized rats. J Clin Invest 80: 1037-1044

9. Fagin JA, Ikejiri K, Levin SR (1987) Insulinotropic effects of vanadate. Diabetes $36: 1448-1452$
10. Gil J, Miralpeix M, Carreras J, Bartrons R (1988) Insulin-like effects of vanadate on glucokinase activity and fructose 2,6-bisphosphate levels in the liver of diabetic rats. J Biol Chem 263: 1868-1871

11. Ramasarma T, Mackellar WC, Grave FL (1981) Vanadate-stimulated NADH oxidation in plasma membrane. Biochem Biophys Acta 646: 88-98

12. Ghanshyam KS, Speeg KV Jr, Cohen S, Garbers DL (1982) Phosphotyrosyl-protein phosphatase of TCRC-2 cells. J Biol Chem 13: 7298-7301

13. Nechay BR, Nanninga LB, Nechay PSE, Post RL, Grantham JJ, Macara IG, Kubena LF, Phillips TD, Nielsen FH (1986) Role of vanadium in biology. Fed Proc 45: 123-132

14. Dubyak GR, Kleinzeller A (1980) The insulin-mimetic effects of vanadate in isolated rat adipocytes. Dissociation from effects of vanadate as a $\left(\mathrm{Na}^{+}-\mathrm{K}^{+}\right)$ATPase inhibitor. $\mathrm{J}$ Biol Chem 255: 5306-5312

15. Tamura S, Brown TA, Whipple JH, Fujita-Yamaguchi $Y$, Dubler RE, Cheng K, Larner J (1984) A novel mechanism for the insulin-like effect of vanadate on glycogen synthase in rat adipocytes. J Biol Chem 259: 6650-6658

16. Green A (1986) The insulin-like effect of sodium vanadate on adipocyte glucose transport is mediated at a post-insulin-receptor level. Biochem J 238: 663-669

17. Simons TJB (1979) Vanadate - a new tool for biologists. Nature 281: $337-338$

18. Macara IG (1986) Activation of ${ }^{45} \mathrm{Ca}^{2+}$ influx and ${ }^{22} \mathrm{Na}^{+} / \mathrm{H}^{+}$exchange by epidermal growth factor and vanadate in A431 cells is independent of phosphatidylinositol turnover and is inhibited by phorbol ester and diacylglycerol. J Biol Chem 261:9321-9327

19. Portha B, Blondel $O(1988)$ Insulin resistance in rats with non-insulin dependent diabetes induced by neonatal ( 5 days) streptozotocin: evidence for reversal following phlorizin treatment. Diabetologia 31: $532 \mathrm{~A}$

Received: 2 September 1988

and in revised form: 27 January 1989

\section{Dr. B. Portha}

Lab. Physiol. Dév.

Université Paris 7

Tour 33-43, ler étage

2 Place Jussieu

F-75251 Paris Cedex 05

France 